\title{
SISTEMA PARA GERAÇÃO, AQUISIÇÃO E PROCESSAMENTO DE SINAIS DE ULTRA-SOM
}

\author{
Amauri A. Assef* \\ amauriassef@yahoo.com.br \\ Pedro M. Gewehr* \\ gewehr@utfpr.edu.br \\ Eduardo T. Costa ${ }^{\dagger}$ \\ educosta@ceb.uni camp.br
}

\author{
Joaquim M. Maia* \\ joaquimeutfpr.edu.br \\ Humberto R. Gamba* \\ humberto@utfpr.edu.br \\ Vera L. S. N. Button \\ vera@ceb.unicamp.br
}

*Universidade Tecnológica Federal do Paraná - UTFPR

Programa de Pós-Graduação em Engenharia Elétrica e Informática Industrial - CPGEI

Departamento Acadêmico de Eletrônica - DAELN

Av. Sete de Setembro, 3165 - Rebouças

80230-901, Curitiba, Paraná, Brasil

${ }^{\dagger}$ Universidade Estadual de Campinas - UNICAMP

Departamento de Engenharia Biomédica - DEB, Faculdade de Engenharia Elétrica e de Computação - FEEC

Centro de Engenharia Biomédica - CEB

Caixa Postal 6040

13084-971, Campinas, São Paulo, Brasil

\section{ABSTRACT}

This work describes a system for generation, acquisition and processing of ultrasonic signals to be used in material characterization. The system can be used in the pulse-echo and transmission-reception modes, with programmable sampling rate between $5 \mathrm{MHz}$ and $80 \mathrm{MHz}$, internal triggering, repetition rate between $111 \mathrm{~Hz}$ and $333 \mathrm{~Hz}$, pulse width of $100 \mathrm{~ns}$ and amplitude of $200 \mathrm{~V}$. The reception circuits operate from $20 \mathrm{kHz}$ to $30 \mathrm{MHz}$, with gain control from $-40 \mathrm{~dB}$ to $+40 \mathrm{~dB}$. In order to evaluate the system performance, the propagation velocity and broadband attenuation of ultrasonic waves BUA were measured in acrylic and water. The results presented deviation below $1 \%$, showing good repeatability and demonstrating that the system can be used in non invasive and non

Artigo submetido em 07/03/2007 (Id.: 00783)

Revisado em 21/02/2008, 09/05/2008, 08/12/2008

Aceito sob recomendação do Editor Associado Prof. Sebastian Yuri Cavalcanti Catunda destructive tests for different material characterization.

KEYWORDS: Ultrasound, speed of sound, broadband ultrasound attenuation, material characterization.

\section{RESUMO}

Este trabalho apresenta um sistema de geração, aquisição e processamento de sinais de ultra-som para caracterização de materiais. O sistema permite operação nos modos pulsoeco e transmissão-recepção, com taxa de amostragem configurável entre $5 \mathrm{MHz}$ e $80 \mathrm{MHz}$, sincronismo interno, taxa de repetição dos pulsos de excitação dos transdutores entre $111 \mathrm{~Hz}$ e $333 \mathrm{~Hz}$, largura do pulso de 100 ns e amplitude de $200 \mathrm{~V}$. Os circuitos de recepção operam na faixa entre $20 \mathrm{kHz}$ e $30 \mathrm{MHz}$, com controle de ganho entre $-40 \mathrm{~dB}$ e +40 dB. Para avaliar o desempenho do sistema, foram realizadas medidas de velocidade de propagação e atenuação em banda larga de ondas ultra-sônicas BUA em acrílico e água. 
Os resultados obtidos apresentaram desvios inferiores a $1 \%$, evidenciando que o sistema apresenta boa repetitividade e pode ser utilizado em testes não invasivos e não destrutivos para caracterização de diferentes materiais.

PALAVRAS-CHAVE: Ultra-som, velocidade de propagação do som, atenuação em banda larga, caracterização de materiais.

\section{INTRODUÇÃO}

Atualmente várias técnicas baseadas em radiação têm sido utilizadas para auxílio no diagnóstico médico, tais como a tomografia por raio- $\mathrm{X}$, tomografia axial computadorizada (TAC), tomografia por emissão de pósitron (TEP), ressonância nuclear magnética (RNM), tomografia ultra-sônica computadorizada (TUC), entre outras (Webb, 1988). Entretanto, na busca contínua por tecnologias mais seguras e simples para aplicação na medicina, o ultra-som vem apresentando um papel cada vez mais importante, sendo atualmente a segunda técnica de formação de imagens mais utilizada clinicamente, preterida apenas pelo raio-X convencional (Shung, 1996).

Desde a década de 50, as técnicas de ultra-som vêm sendo aplicadas, com sucesso, em diversas áreas para testes e exames de várias estruturas. Dentre as aplicações principais do ultra-som, pode-se relacionar: medições de distâncias, espessuras, áreas e volumes, verificação de descontinuidade e rugosidade (corrosão) de materiais, determinação de falhas na geometria de um objeto, testes não destrutivos em materiais como polímeros e madeiras, e verificações na forma de estruturas submersas. Pode-se citar como áreas que utilizam o ultra-som em suas pesquisas, a medicina, a oceanografia, a metalurgia, a mecânica e a química, entre outras (Duarte et alii, 1999; Grimm e Williams, 1993).

Técnicas de caracterização de meios biológicos baseadas em ultra-som são amplamente utilizadas nas indústrias de alimentos e bebidas. Particularmente, o leite bovino tem sido objeto de diversos estudos onde são investigadas propriedades como, por exemplo, distribuição do tamanho das partículas de gordura emulsionadas, extrato seco desengordurado e água adicionada ao leite (Dorabiato, 2007; Dorabiato et alii, 2006; Higuti et alii, 1999).

A utilização de sensores ultra-sônicos para determinação da densidade de diferentes líquidos tem importância significativa para o processo de automação, principalmente nas indústrias química e do petróleo. A técnica permite a monitoração de tubos com diâmetro superior a $60 \mathrm{~mm}$ sem perda de pressão, superando a limitação dos equipamentos de densitometria e medidores de fluxo volumétrico (Adamowski et alii, 1995).
$\mathrm{Na}$ área médica, pesquisas in vivo (Langton et alli, 1984) vêm sendo realizadas de forma a padronizar a utilização da técnica ultra-sônica e têm mostrado que a mesma apresenta características que tornam vantajosa a sua utilização em procedimentos médicos, tais como baixo custo, portabilidade, facilidade de manuseio, possibilidade de se conseguir gerar imagens em tempo real e prover informações das propriedades elásticas dos tecidos (algumas imperceptíveis através do raio-X), ser um método não invasivo e principalmente à sua característica de radiação não ionizante, o que permite a repetição dos testes com segurança (Hull et alii, 1996; Nicholson et alii, 1997; Njeh et alli, 2001).

A utilização do ultra-som como método para diagnóstico médico também tem gerado grande interesse devido ao baixo custo e por sua característica não ionizante. O método utiliza a velocidade de propagação do som e a atenuação em banda larga (BUA - Broadband Ultrasonic Attenuation), que corresponde à expressão da taxa de atenuação em uma determinada faixa de freqüências das ondas de pressão, para acessar informações sobre a estrutura de tecidos e órgãos (Strelitzki e Evans, 1996; Maia, 2001).

Este trabalho apresenta a concepção e o desenvolvimento de um sistema de geração, aquisição e processamento digital de sinais de ultra-som, utilizando o DSP TMS320VC5416 e um microcomputador com o software Matlab (The MathWorks, Inc.), para o cálculo da velocidade de propagação acústica em diferentes materiais e processamento matemático da curva de atenuação em função da freqüência para obtenção do parâmetro BUA. Serão apresentadas nas próximas seções a descrição das técnicas de ultra-som e a análise detalhada do sistema desenvolvido, com o objetivo de ilustrar as características do mesmo.

\section{MÉTODOS PARA CARACTERIZAÇÃO DE MEIOS ATRAVÉS DE ULTRA-SOM}

As ondas ultra-sônicas podem sofrer reflexão, refração ou difração quando o feixe encontra uma interface entre meios com características acústicas diferentes. Baseados nesse comportamento, dois métodos experimentais são geralmente utilizados para caracterização de meios biológicos e não biológicos por ultra-som: o método transmissão-recepção e o método pulso-eco (reflexão). A combinação desses dois métodos permite obter informações sobre distância entre objetos, velocidade de propagação e atenuação de ondas ultrasônicas nos meios (Maia, 2001).

\subsection{Método transmissão-recepção}

No método transmissão-recepção, apresentado no esquema da Figura 1, é utilizado dois transdutores independentes para 


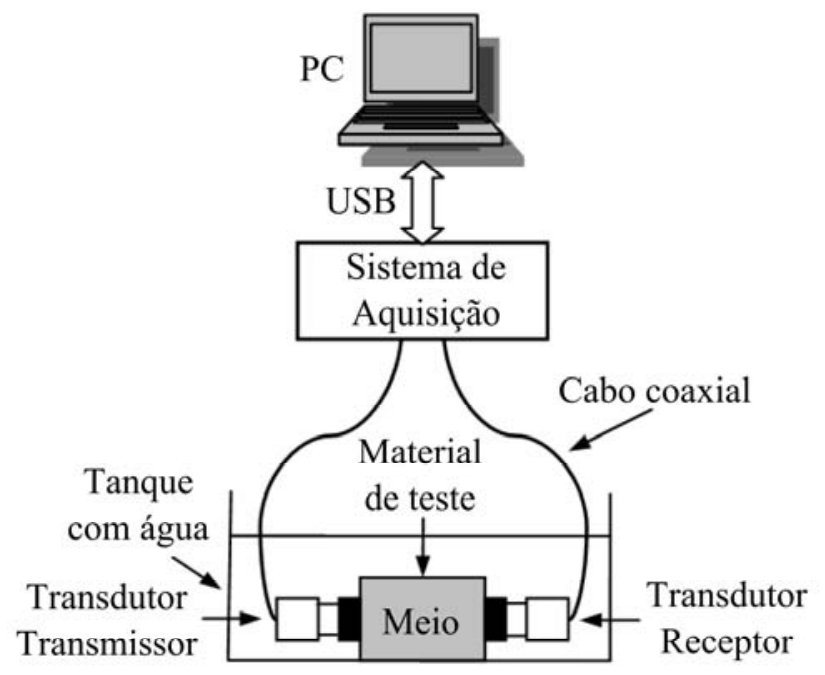

Figura 1: Método transmissão-recepção.

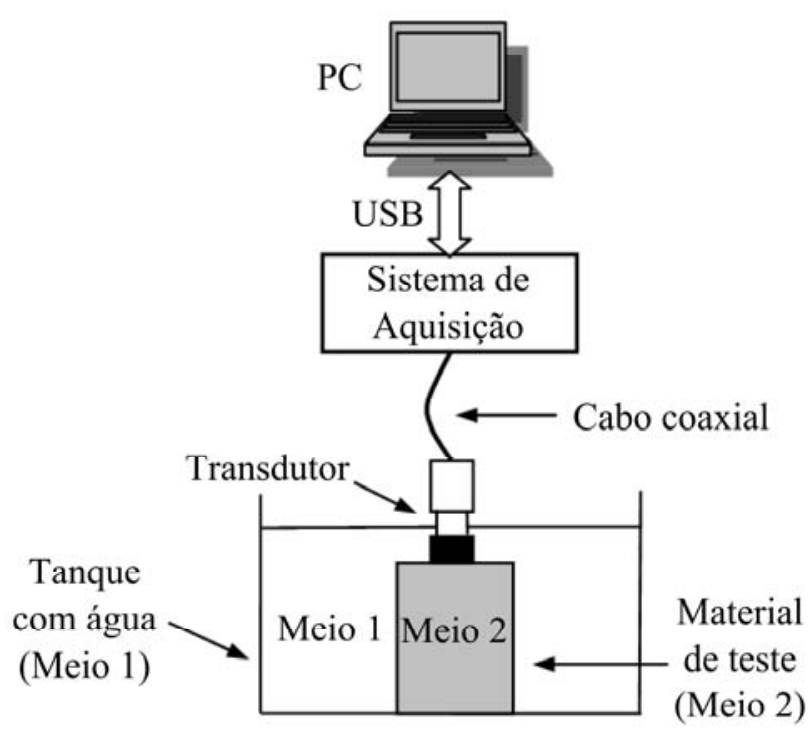

Figura 2: Método pulso-eco.

Tabela 1: Especificações de requisitos do sistema captada no transdutor receptor.

\subsection{Método pulso-eco}

No método pulso-eco, apresentado no esquema da Figura 2, o mesmo transdutor atua como transmissor e como receptor de ondas ultra-sônicas. Nesse caso, um pulso elétrico é aplicado ao transdutor e esse gera uma onda ultra-sônica. A onda ultra-sônica propaga-se através do meio 1 e, assim que encontra a interface entre os meios 1 e 2 , parte da onda é refletida e outra se propaga através do meio 2. Da mesma forma, a onda que se propaga através do meio 2 , ao encontrar outra interface, terá parte refletida e parte transmitida. As ondas refletidas que são captadas pelo transdutor trazem informações sobre a distância ou a velocidade de propagação. Também é possível obter informações sobre atenuação processando-se os ecos recebidos. Conhecendo-se a velocidade de propagação nos meios, pode-se determinar a distância percorrida pelas ondas utilizando-se o tempo decorrido entre a excitação do transdutor e o instante em que as ondas refletidas são captadas.

\section{ESPECIFICAÇÃO DE REQUISITOS}

Para a concepção e desenvolvimento do sistema foi definida inicialmente a especificação de requisitos. Esta especificação é apresentada na Tabela 1 com as definições dos parâmetros necessários para a aquisição, processamento e estudo dos sinais ultra-sônicos. Além disso, foram definidas as interfaces físicas para controle e sinalização do sistema.

\begin{tabular}{|l|l|}
\hline Item & Especificação \\
\hline 1 & $\begin{array}{l}\text { Indicação visual do estado do equipamento e } \\
\text { configuraçães através de um display de cristal } \\
\text { líquido e 2 LEDs }\end{array}$ \\
\hline 2 & $\begin{array}{l}\text { Controle das funções do sistema através de } 4 \\
\text { chaves tipo push-button }\end{array}$ \\
\hline 3 & Comunicação serial através de interface USB \\
\hline 5 & $\begin{array}{l}\text { Seleção de taxa de amostragem entre 5 MHz e } \\
80 \text { MHz }\end{array}$ \\
\hline 6 & $\begin{array}{l}\text { Controle da freqüência de repetição dos pulsos } \\
\text { gerados com sincronismo interno entre 111 Hz } \\
\text { e 333 Hz, ou pulso único }\end{array}$ \\
\hline 7 & $\begin{array}{l}\text { Seleção dos ganhos dos circuitos da unidade de } \\
\text { recepção entre -40 dB e +40 dB }\end{array}$ \\
\hline 8 & $\begin{array}{l}\text { Controle de sincronismo com atraso programá- } \\
\text { vel }\end{array}$ \\
\hline 9 & $\begin{array}{l}\text { Dois modos de operação configuráveis: } \\
\text { transmissão-recepção ou pulso-eco }\end{array}$ \\
\hline $\begin{array}{l}\text { Cálculo dos parâmetros de velocidade de pro- } \\
\text { pagação e atenuação das ondas ultra-sônicas, e } \\
\text { medida dos BUA de diferentes materiais }\end{array}$ \\
\hline
\end{tabular}

\section{METODOLOGIA}

Com base nas especificações apresentadas na seção anterior, foi realizada uma pesquisa sobre os módulos de hardware, software e componentes necessários para o projeto, resul- 
tando nos módulos descritos nesta seção.

Para a implementação do protótipo foi adotada como placamãe do sistema, a DSK (DSP Starter Kit) TMS320VC5416. A placa utiliza o DSP (Digital Signal Processor) TMS320VC5416 que atende todos os pré-requisitos de hardware e elevado desempenho para o controle e gerenciamento dos circuitos do sistema. Além disso, o kit de desenvolvimento da empresa Texas Instruments, apresenta interface USB (Universal Serial Bus), permitindo a comunicação com um microcomputador para processamento e análise dos sinais de ultra-som.

Na parte do software, devido à sua elevada capacidade de processamento matemático, foi adotado o Matlab para tratamento dos sinais digitalizados pela unidade de recepção do sistema, cálculo dos parâmetros de velocidade do sinal de propagação no meio e BUA, e análises estatísticas.

Os circuitos eletrônicos desenvolvidos para o sistema foram montados na placa-filha Interface_V1, que é interligada à placa-mãe DSK através de dois conectores de expansão. A placa-filha é composta pelos circuitos da lógica de apoio e controle, unidade de transmissão e geração dos pulsos elétricos de alta amplitude para excitação do transdutor transmissor, unidade de recepção com circuitos de proteção e amplificação, conversor A/D (analógico para digital) de alta velocidade, memória FIFO (First-In-First-Out) para armazenamento do buffer de dados digitalizados, display de cristal líquido (LCD - Liquid Crystal Display) para a apresentação das informações do sistema, chaves tipo push-button para seleção de funções e configurações, LEDs (Light Emitting Diode) e campainha (buzzer) para sinalização. O diagrama em blocos do sistema de ultra-som completo é apresentado na Figura 3.

\subsection{Unidade de Controle}

A Figura 4 apresenta o diagrama em blocos da configuração básica da unidade de controle do sistema. A unidade de controle digital é representada pela placa DSK TMS320VC5416, circuitos decodificadores, e portas de entrada e saída (E/S) da placa Interface_V1. Esta unidade é responsável pela execução das tarefas de controle dos circuitos de transmissão e recepção, gerenciamento da entrada de comandos e configurações, realizadas de forma local através de 4 chaves, apresentação das informações do sistema em um LCD, sinalização dos 2 LEDs e buzzer, geração da freqüência de amostragem na faixa de $5 \mathrm{MHz}$ a $80 \mathrm{MHz}$ para o conversor A/D e memória FIFO, e sincronismo para leitura da memória FIFO.

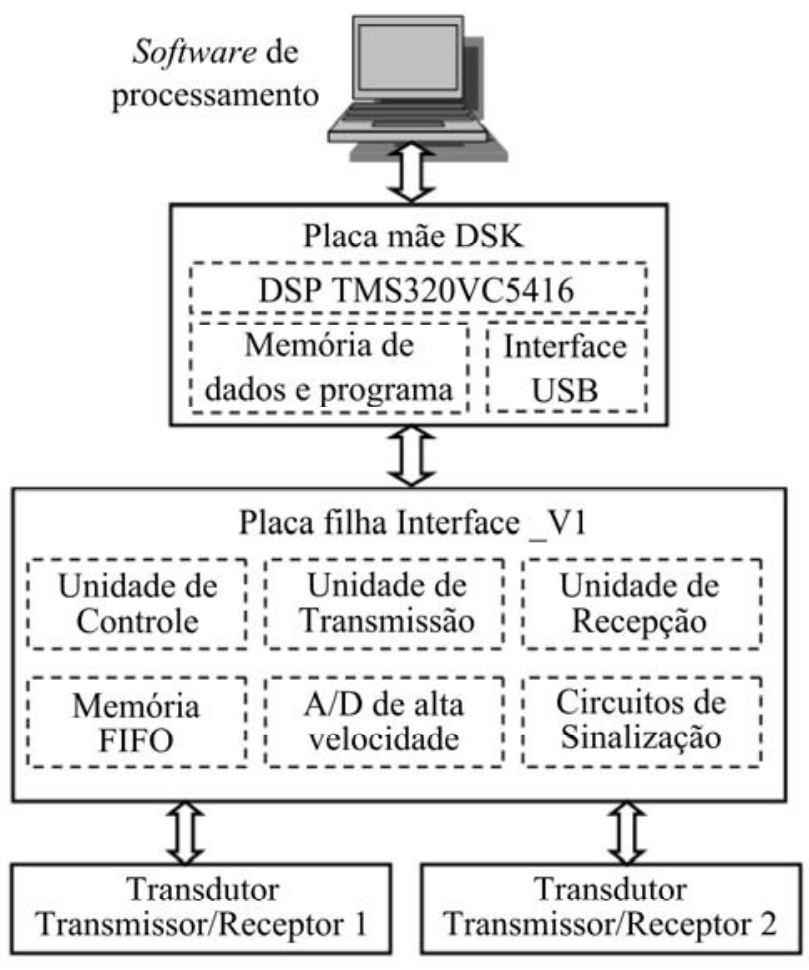

Figura 3: Diagrama em blocos do sistema desenvolvido.

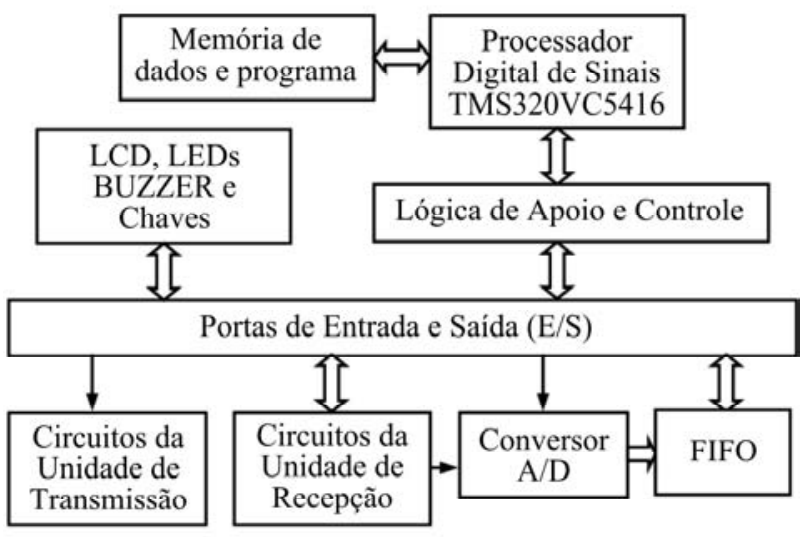

Figura 4: Diagrama em blocos da unidade de controle.

\subsection{Unidade de Transmissão}

A unidade de transmissão foi projetada para gerar e transmitir os pulsos de alta amplitude que excitam o transdutor transmissor, com taxa de repetição e modo de operação transmissão-recepção ou pulso-eco, configuráveis através das chaves de comando. A Figura 5 mostra o diagrama em blocos dos circuitos de transmissão. Esta unidade é composta por um circuito de disparo, buffer conversor de nível lógico, driver de corrente, circuito de potência, circuito de seleção dos transdutores e circuito de corte. A taxa de transmis- 


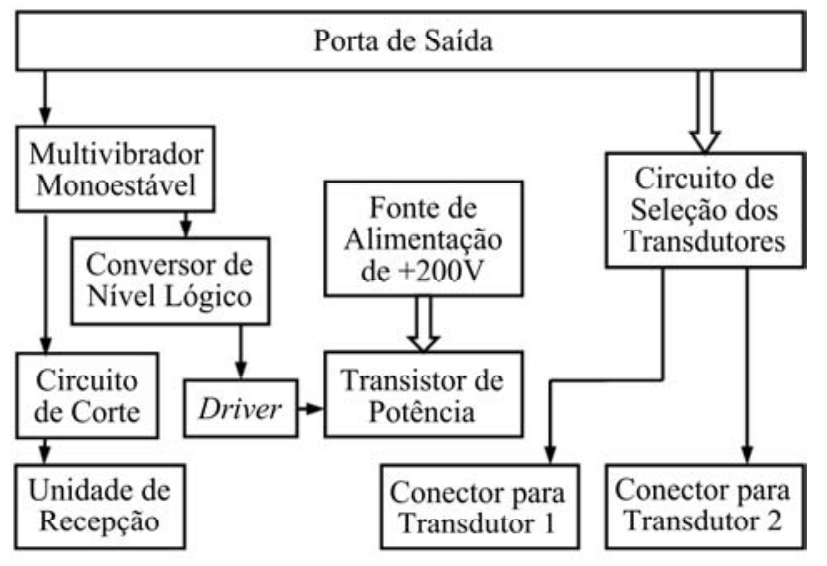

Figura 5: Diagrama em blocos da unidade de transmissão.

são dos pulsos é controlada pelo DSP na faixa entre $111 \mathrm{~Hz}$ e $333 \mathrm{~Hz}$, ou disparo único após comando de início de teste.

A entrada da unidade de transmissão é representada pelo circuito de disparo. Esse circuito é composto por um multivibrador na configuração monoestável que recebe o comando da unidade de controle e gera um pulso estreito, com largura aproximada de $100 \mathrm{~ns}$. Esse pulso é aplicado ao circuito formado por um buffer de tensão e um driver de corrente que condiciona o sinal para disparar o transistor de potência IRF840 acoplado a uma fonte de tensão de $+200 \mathrm{Vcc}$, para geração dos pulsos de alta amplitude. A fonte de alta tensão foi desenvolvida utilizando um transformador isolador com 220 Vac no enrolamento primário, e dois enrolamentos secundários de 200 Vac e 12 Vac, e uma placa de circuito impresso com o regulador de tensão LM723, da National Semiconductor (2005), que aciona um transistor de potência TIP 50, realizando uma regulação linear da tensão de saída em +200 Vcc. A saída do circuito de potência é aplicada ao circuito de seleção dos transdutores, composto por dois relés de dois contatos cada, permitindo que os transdutores possam operar em modo transmissão-recepção ou pulso-eco. Em ambos os modos, o transdutor de recepção fica conectado ao circuito de proteção da unidade de recepção. O primeiro multivibrador gera o sinal de sincronismo para o disparo do segundo circuito multivibrador monoestável, que envia o sinal para o circuito de corte com pulso de largura aproximadamente 50 vezes maior que o pulso de transmissão, fazendo com que durante a geração do pulso de alta amplitude o estágio de recepção atenue em $40 \mathrm{~dB}$ o sinal na sua entrada, protegendo o amplificador de recepção e também evitando que o mesmo sature.

\subsection{Unidade de Recepção}

A unidade de recepção, mostrada no diagrama em blocos da Figura 6, é responsável por receber e amplificar, conforme a

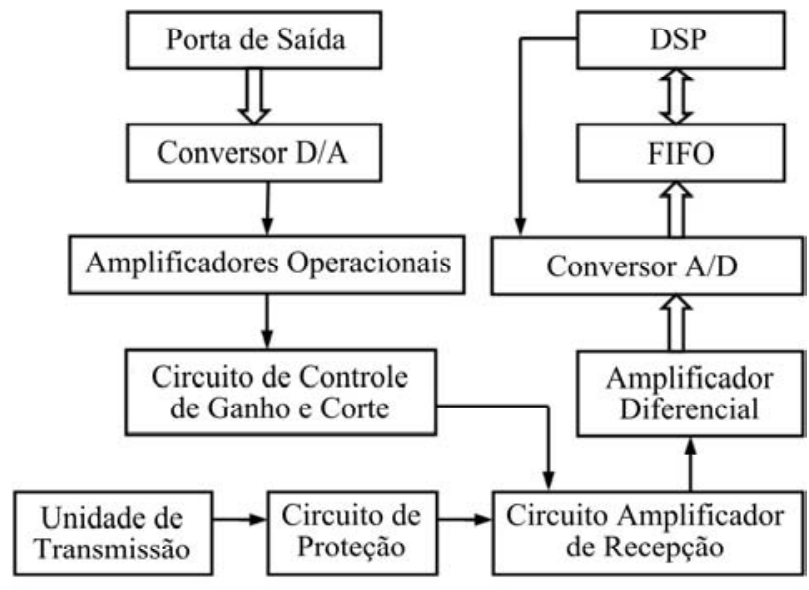

Figura 6: Diagrama em blocos da unidade de recepção.

configuração do sistema, os sinais captados por um transdutor conectado à sua entrada. Esta unidade é formada pelos circuitos de proteção contra sobretensão, conversor D/A para controle de ganho do circuito amplificador de recepção, conversor A/D de alta velocidade e memória FIFO para armazenamento do buffer de dados digitalizados.

$\mathrm{Na}$ operação em modo pulso-eco, o transdutor que é excitado com os pulsos elétricos de alta amplitude é o mesmo que capta os sinais de ultra-som. Com isso, é necessário um circuito de proteção para evitar que a alta tensão de excitação danifique o circuito amplificador. Após o sinal recebido passar pelo circuito de proteção, é condicionado através do amplificador de banda larga com ganho controlado por tensão, VCA610, que permite a amplificação do sinal em uma faixa entre $-40 \mathrm{~dB}$ a $+40 \mathrm{~dB}$. A tensão analógica para controle do ganho do circuito amplificador varia entre $-2 \mathrm{~V}$ e $0 \mathrm{~V}$, sendo obtida por um circuito conversor D/A controlado pelo DSP. O sinal de saída do circuito amplificador de recepção é aplicado em um amplificador diferenciador, necessário para a entrada simétrica do conversor A/D. Esse conversor opera em alta freqüência e é interligado à memória FIFO, utilizada para sincronizar a leitura do buffer de dados entre o conversor A/D e o DSP.

\subsection{Circuito Conversor A/D}

O circuito conversor A/D foi desenvolvido com um amplificador conversor de entrada simples para diferencial e um conversor A/D de alta velocidade, para permitir a utilização do sistema em pesquisas com transdutores de ultra-som com freqüência central até $30 \mathrm{MHz}$, captação e análise de sinais harmônicos, e estudo das não-linearidades dos sinais. O conversor A/D utilizado no sistema é o ADS5410, da Texas Instruments, com arquitetura interna pipeline de múltiplos estágios em cascata, possibilitando alto desempenho com taxa de 
amostragem de 80 milhões de amostras por segundo, largura de banda de $1 \mathrm{GHz}$, resolução de 12 bits, ENOB (número de bits efetivo) de 10,5 bits, geração da referência para conversão de tensão, entrada em modo diferencial e saída em complemento de dois, ideal para aplicações de imagens médicas por ultra-som. O controle interno analógico do ADS5410 é alimentado com tensão de $+3,3 \mathrm{~V}$ e a parte de controle interno digital opera com alimentação de $+1,8 \mathrm{~V}$, obtida pelo regulador de tensão TPS76718 a partir da tensão de $+3,3 \mathrm{~V}$. As entradas do conversor são diferenciais, centradas na tensão de modo comum (VCM) de $+1,8 \mathrm{~V}$ gerada pelo próprio dispositivo. A tensão de fundo de escala para o modo diferencial é obtida com as duas entradas, positiva VINP e negativa VINN, simétricas em VCM + 0,5 V e VCM - 0,5 V, respectivamente. A freqüência de clock para o funcionamento do conversor varia entre $5 \mathrm{MHz}$ e $80 \mathrm{MHz}$, sendo configurada pelo sistema e gerada pelo DSP. Para evitar ao máximo os ruídos, como o do chaveamento do clock, foram montados vários capacitores multicamadas de $100 \mathrm{nF}$ e de tântalo de $10 \mu \mathrm{F}$ em paralelo, próximos aos pinos de alimentação do conversor A/D. Como o modo de entrada do conversor é diferencial, foi utilizado o amplificador THS4503, com ganho unitário, para converter a saída do circuito amplificador VCA610, de saída simples para diferencial, com a relação largura de banda versus ganho constante até a freqüência de $30 \mathrm{MHz}$ e atenuação do sinal de saída em aproximadamente $10 \mathrm{~dB}$ para $100 \mathrm{MHz}$. O circuito de conexão entre o amplificador diferencial e o conversor A/D foi implementado com base no manual da placa de conversão ADS5410 EVM, desenvolvida pela Texas Instruments (2002).

\subsection{Memória FIFO}

No circuito de recepção, o sinal de ultra-som é condicionado e enviado para o circuito conversor A/D com taxa de amostragem entre $5 \mathrm{MHz}$ e $80 \mathrm{MHz}$. O próximo passo seria conectar o conversor A/D diretamente ao barramento do DSP para permitir a aquisição dos dados em alta velocidade. Porém, para a freqüência de $80 \mathrm{MHz}$, o DSP que opera no sistema com barramento interno de $160 \mathrm{MHz}$, teria que realizar uma operação de leitura do conversor A/D a cada dois ciclos internos, o que não é possível devido à latência que limita a largura de banda das operações de E/S. Para solucionar esse problema foi introduzida a memória FIFO de alta velocidade SN74V245 com a função de armazenar um grande bloco de dados digitalizados e permitir que o DSP realize a leitura de dados em uma velocidade mais baixa. A FIFO SN74V245 é uma memória síncrona com 4096 endereços de 18 bits, que suporta freqüências de clock até $133 \mathrm{MHz}$, com tempo de acesso para leitura de $5 \mathrm{~ns}$.

\subsection{Circuitos de sinalização}

A entrada de comandos e seleção de parâmetros é realizada através da varredura de 4 chaves do tipo push-button normalmente aberta. Quando uma chave ativa é pressionada, o buzzer, que representa a sinalização sonora do sistema, é acionado por $50 \mathrm{~ms}$.

Para as informações de configuração e controle do sistema foi utilizado um LCD de 16 colunas e duas linhas com backlight, padrão Hitashi HD44780. Além do LCD a sinalização visual é realizada por meio de 2 LEDs verdes. Quando o software da placa estiver funcionando, o primeiro LED permanece piscando com intervalo de $200 \mathrm{~ms}$. O segundo LED é aceso somente quando a placa está realizando o teste de ultra-som.

\section{DESCRIÇÃO DOS TESTES REALIZA- DOS}

Para avaliar o hardware desenvolvido, foram realizados testes de medição da velocidade do som na água e em um tarugo cilíndrico de acrílico (polimetil-metacrilato - PMMA), com diâmetro e comprimento de $5 \mathrm{~cm}$, e do parâmetro BUA, no último. Os testes foram realizados em um tanque de plástico, com um par de transdutores de ultra-som, com frequiência central de $500 \mathrm{kHz}$ e $48 \%$ de largura de banda, modelo V318, da empresa Panametrics, imersos em aproximadamente 25 litros de água, com as temperaturas do meio medidas por um termômetro de mercúrio.

No cálculo da velocidade de propagação da onda na água e no tarugo de acrílico, os transdutores foram posicionados em distâncias conhecidas. A partir do comando de início do teste, o sistema sincroniza o pulso de excitação do transdutor transmissor com o ponto máximo do envelope do pulso de aquisição, sendo esse obtido matematicamente através da Transformada de Hilbert (Oppenhein e Schafer, 1975), conforme o exemplo da Figura 7. Com isso, a velocidade de propagação no meio é calculada através do quociente entre o tempo de propagação dos sinais de ultra-som e a distância de separação entre o par de transdutores, com unidade em m/s.

Para determinar o BUA do acrílico, foram adquiridos os sinais propagados no meio de referência (água) e no acrílico, utilizando-se o método transmissão-recepção, com distância de $5 \mathrm{~cm}$, conforme mostra a comparação da Figura 8. Após a aquisição, os espectros de freqüência dos sinais do meio de referência $\left(V_{r}\right)$ e do material $\left(V_{m}\right)$ foram determinados através do processamento da Transformada Rápida de Fourier (FFT), no microcomputador, sendo a curva de atenuação em função da freqüência $\alpha(f)$ do material, apresentada na Figura 14, calculada através da Equação 1: 


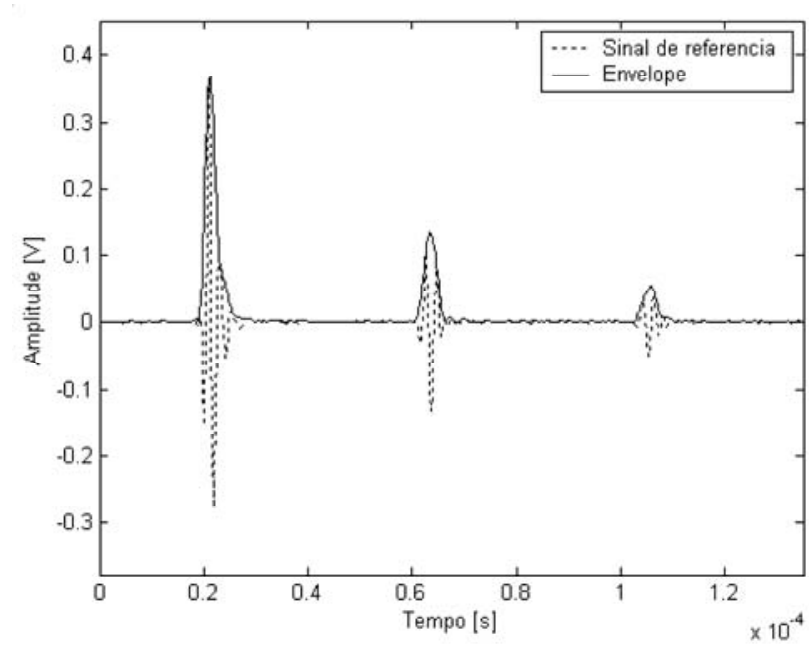

Figura 7: Sinal ultra-sônico (tracejado) e seu envelope (contínuo) obtido através da Transformada de Hilbert.

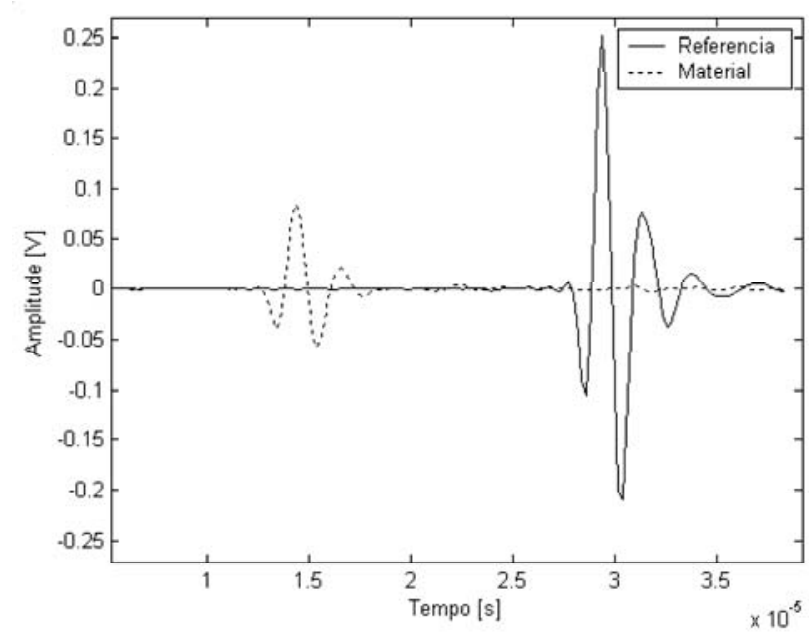

Figura 8: Sinal de referência (contínuo) e sinal transmitido através do material de teste (tracejado).

$$
\alpha(f)=\left|20 \log _{10}\right| V_{r}\left|-20 \log _{10}\right| V_{m}||
$$

Na curva de atenuação em função da freqüência $\alpha(f)$, existe uma região que apresenta uma relação aproximadamente linear. Os valores desta região são ajustados em uma linha reta, entre as frequiências de $200 \mathrm{kHz}$ e $700 \mathrm{kHz}$, para os transdutores com freqüência central de $500 \mathrm{kHz}$. O valor do BUA é determinado através da taxa de inclinação (coeficiente angular) da reta de regressão linear obtida, com unidade em $\mathrm{dB} / \mathrm{MHz}$.

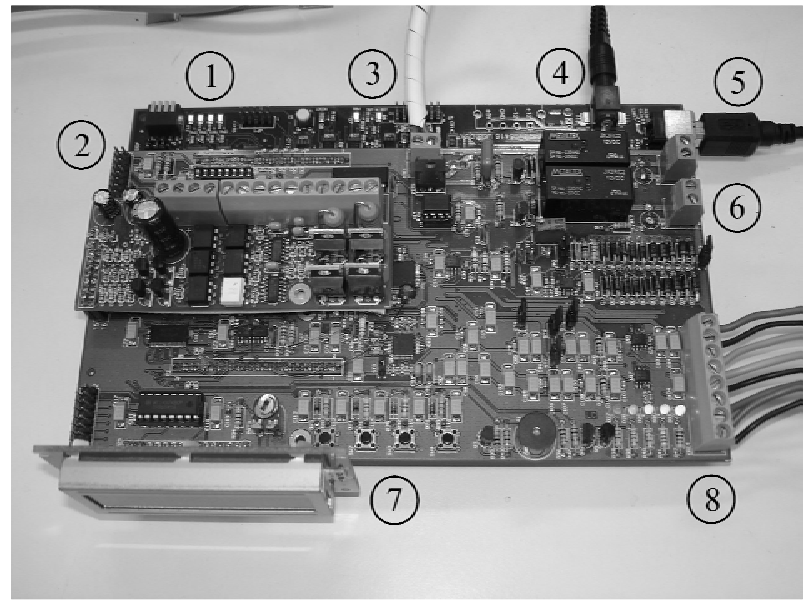

Figura 9: Foto do hardware do sistema de ultra-som.

\section{RESULTADOS EXPERIMENTAIS}

A Figura 9 mostra a foto do hardware, com dimensão de 210 (C) x 110 (L) x 40 (A) (mm), e a Tabela 2 apresenta os principais componentes do sistema.

A Figura 10 mostra, no canal $1(\mathrm{CH} 1)$ da tela do osciloscópio, o sinal TTL na saída do primeiro circuito multivibrador, que é utilizado para disparar o circuito de potência para geração do pulso elétrico de alta amplitude na unidade de transmissão, apresentado no canal $(\mathrm{CH} 2)$, com o transdutor desconectado do circuito. Esse pulso possui polaridade negativa com amplitude máxima de $-210 \mathrm{~V}$ e largura de 98 ns.

As Figuras 11 e 12 apresentam o sinal ultra-sônico captado pelo transdutor receptor, no modo transmissão-recepção, a uma distância de $3,2 \mathrm{~cm}$, utilizando como meio a água. A Figura 11 mostra o sinal no conector do transdutor receptor obtido pelo osciloscópio. A Figura 12 apresenta o sinal digitalizado pelo sistema de aquisição e enviado ao microcomputador onde é realizado o processamento digital do sinal para obtenção dos parâmetros desejados utilizando-se o software Matlab. O sistema foi configurado com ganho de $+10 \mathrm{~dB}$, sem atraso, com disparo único e frequiência de amostragem de $5 \mathrm{MHz}$.

Para cada teste foram processadas dez aquisições e verificados os valores máximo, mínimo, média e média total entre as medidas, para as taxas de amostragem de 5, 10, 20, 40 e $80 \mathrm{MHz}$, do parâmetro velocidade de som e, nas três primeiras taxas, para o parâmetro BUA. Além disso, são apresentados os desvios padrão (DP) em relação aos valores médios de cada taxa e dos valores médios totais entre as medidas.

As Tabelas 3 e 4 apresentam os resultados da velocidade de propagação da onda ultra-sônica, utilizando o método 
Tabela 3: Velocidade de propagação da onda ultra-sônica $(\mathrm{m} / \mathrm{s})$ calculada pelo método transmissão-recepção, na água a $26^{\circ} \mathrm{C}$.

\begin{tabular}{|l|l|l|l|l|l|}
\hline \multirow{2}{*}{ Resultados } & \multicolumn{5}{|c|}{ Freqüências de amostragem } \\
\cline { 2 - 6 } & $\mathbf{5} \mathbf{~ M H z}$ & $\mathbf{1 0} \mathbf{~ M H z}$ & $\mathbf{2 0} \mathbf{~ M H z}$ & $\mathbf{4 0} \mathbf{~ M H z}$ & $\mathbf{8 0} \mathbf{~ M H z}$ \\
\hline Máximo & 1511 & 1511 & 1509 & 1507 & 1504 \\
\hline Mínimo & 1503 & 1507 & 1507 & 1506 & 1503 \\
\hline Média \pm DP & $1505 \pm 3$ & $1508 \pm 2$ & $1508 \pm 1$ & $1506 \pm 1$ & $1504 \pm 1$ \\
\hline Média total \pm DP & $1506 \pm 3$ & \multicolumn{7}{|l|}{} \\
\hline
\end{tabular}

Tabela 4: Velocidade de propagação da onda ultra-sônica $(\mathrm{m} / \mathrm{s})$ calculada pelo método transmissão-recepção, no acrílico a $27^{\circ} \mathrm{C}$.

\begin{tabular}{|l|l|l|l|l|l|}
\hline \multirow{2}{*}{ Resultados } & \multicolumn{5}{|c|}{ Freqüências de amostragem } \\
\cline { 2 - 6 } & $\mathbf{5} \mathbf{~ M H z}$ & $\mathbf{1 0} \mathbf{~ M H z}$ & $\mathbf{2 0} \mathbf{~ M H z}$ & $\mathbf{4 0} \mathbf{~ M H z}$ & $\mathbf{8 0} \mathbf{~ M H z}$ \\
\hline Máximo & 2684 & 2697 & 2691 & 2684 & 2682 \\
\hline Mínimo & 2657 & 2684 & 2677 & 2677 & 2657 \\
\hline Média \pm DP & $2678 \pm 11$ & $2686 \pm 6$ & $2682 \pm 5$ & $2678 \pm 2$ & $2671 \pm 8$ \\
\hline Média total \pm DP & $2679 \pm 9$ & \multicolumn{7}{|l|}{} \\
\hline
\end{tabular}

Tabela 2: Principais componentes do sistema.

\begin{tabular}{|l|l|}
\hline Item & Especificação \\
\hline 1 & Placa-filha Interface_V1 (superior) \\
\hline 2 & Placa-mãe DSK TMS320VC5416 (inferior) \\
\hline 3 & Entrada da fonte de +200 Vcc \\
\hline 4 & Entrada da fonte de +12 Vcc da placa DSK \\
\hline 5 & Conector USB \\
\hline 6 & Conectores de entrada dos transdutores \\
\hline 7 & LCD e chaves \\
\hline 8 & Entrada das fontes dos circuitos lógicos \\
\hline
\end{tabular}

transmissão-recepção, na água e no tarugo de acrílico, respectivamente. As tabelas apresentam os valores para os transdutores distanciados $5 \mathrm{~cm}$, com o sistema configurado para ganho de $+10 \mathrm{~dB}$ e disparo único. Os resultados para o método pulso-eco nas mesmas configurações, utilizando apenas um transdutor, são apresentados nas Tabelas 5 e 6.

Para determinar o BUA do acrílico, foram adquiridos, pelo sistema de ultra-som, os sinais propagados no meio de referência (água) e no tarugo cilíndrico de acrílico com $5 \mathrm{~cm}$ de comprimento e diâmetro, imerso no tanque com água. Após isto, foram calculados os espectros de frequiência dos dois sinais, para a mesma faixa de freqüência, com resultado apre-

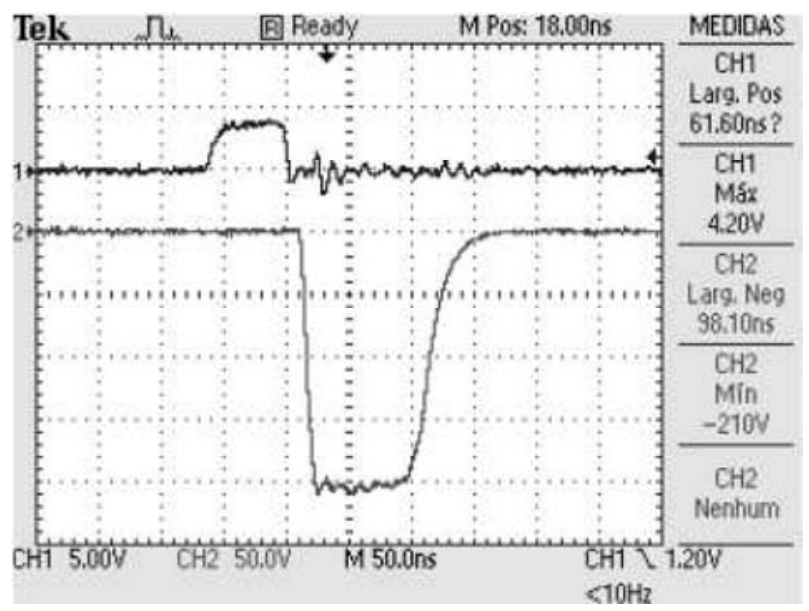

Figura 10: Sinal de saída do primeiro circuito multivibrador (CH1) e pulso elétrico de alta amplitude gerado na unidade de transmissão $(\mathrm{CH} 2)$.

sentado na Figura 13.

Após o cálculo da curva de atenuação em função da freqüência $\alpha(f)$ do acrílico, processada através da subtração dos valores absolutos das FFTs do sinal de referência e do sinal no material, foram obtidos os resultados do BUA para o material, apresentados na Tabela 7.

A Figura 14 apresenta a curva $\alpha(f)$ do acrílico e também a 
Tabela 5: Velocidade de propagação da onda ultra-sônica $(\mathrm{m} / \mathrm{s})$ calculada pelo método pulso-eco, na água a $26^{\circ} \mathrm{C}$.

\begin{tabular}{|l|l|l|l|l|l|}
\hline \multirow{2}{*}{ Resultados } & \multicolumn{5}{|c|}{ Frequiências de amostragem } \\
\cline { 2 - 6 } & $\mathbf{5} \mathbf{~ M H z}$ & $\mathbf{1 0} \mathbf{~ M H z}$ & $\mathbf{2 0} \mathbf{~ M H z}$ & $\mathbf{4 0} \mathbf{~ M H z}$ & $\mathbf{8 0} \mathbf{~ M H z}$ \\
\hline Máximo & 1510 & 1510 & 1511 & 1510 & 1510 \\
\hline Mínimo & 1506 & 1508 & 1509 & 1509 & 1509 \\
\hline Média \pm DP & $1510 \pm 1$ & $1510 \pm 1$ & $1510 \pm 1$ & $1509 \pm 0$ & $1509 \pm 0$ \\
\hline Média total \pm DP & $1510 \pm 1$ & \multicolumn{7}{|l|}{} \\
\hline
\end{tabular}

Tabela 6: Velocidade de propagação da onda ultra-sônica $(\mathrm{m} / \mathrm{s})$ calculada pelo método pulso-eco, no acrílico a $26^{\circ} \mathrm{C}$.

\begin{tabular}{|l|l|l|l|l|l|}
\hline \multirow{2}{*}{ Resultados } & \multicolumn{5}{|c|}{ Freqüiências de amostragem } \\
\cline { 2 - 6 } & $\mathbf{5} \mathbf{~ M H z}$ & $\mathbf{1 0} \mathbf{~ M H z}$ & $\mathbf{2 0} \mathbf{~ M H z}$ & $\mathbf{4 0} \mathbf{~ M H z}$ & $\mathbf{8 0} \mathbf{~ M H z}$ \\
\hline Máximo & 2703 & 2695 & 2695 & 2694 & 2694 \\
\hline Mínimo & 2688 & 2688 & 2692 & 2690 & 2690 \\
\hline Média \pm DP & $2694 \pm 8$ & $2695 \pm 2$ & $2693 \pm 2$ & $2692 \pm 1$ & $2693,9 \pm 1$ \\
\hline Média total \pm DP & $2693 \pm 4$ & \multicolumn{7}{|l|}{} \\
\hline
\end{tabular}

Tabela 7: Resultado do BUA para o acrílico (dB/MHz).

\begin{tabular}{|l|l|l|l|}
\hline \multirow{2}{*}{ Resultados } & \multicolumn{3}{|c|}{ Freqüências de amostragem } \\
\cline { 2 - 4 } & $\mathbf{5} \mathbf{~ M H z}$ & $\mathbf{1 0} \mathbf{~ M H z}$ & $\mathbf{2 0} \mathbf{~ M H z}$ \\
\hline Máximo & 17,6 & 17,1 & 17,6 \\
\hline Mínimo & 16,4 & 16,3 & 16,5 \\
\hline Média \pm DP & $16,9 \pm 0,5$ & $16,8 \pm 0,3$ & $16,9 \pm 0,4$ \\
\hline Média total \pm DP & $16,9 \pm 0,4$ & \\
\hline
\end{tabular}

reta de regressão que melhor se ajusta aos pontos dessa, na faixa entre $200 \mathrm{kHz}$ e $700 \mathrm{kHz}$, sendo o respectivo coeficiente angular equivalente ao parâmetro BUA.

\section{CONCLUSÕES}

Neste trabalho, foi descrito um sistema completo, bastante confiável, compacto e flexível, com capacidade para aquisição e processamento dos sinais em tempo real para estudo e análise de parâmetros ultra-sônicos, e caracterização de materiais e meios.

Através da análise dos resultados obtidos pelo sistema podese verificar que o desvio padrão experimental da média, para o parâmetro velocidade de propagação da água e do acrílico, é inferior a $0,5 \%$. Nos estudos apresentados por Wells (1993) e Bronzino (1986), a velocidade do som na água pode variar entre $1480 \mathrm{~m} / \mathrm{s}$ e $1520 \mathrm{~m} / \mathrm{s}\left(20^{\circ} \mathrm{C}\right)$. No sistema apresentado, os valores médios calculados para esse parâme- tro, nos métodos transmissão-recepção e pulso-eco, foram de $1506 \mathrm{~m} / \mathrm{s}$ e $1510 \mathrm{~m} / \mathrm{s}$, respectivamente. Segundo a literatura científica, avelocidade de propagação do som no acrílico pode varia de $2680 \mathrm{~m} / \mathrm{s}$ (Kino, 1987; Wells, 1977) a $2690 \mathrm{~m} / \mathrm{s}$ (Kane, 2002), enquanto o sistema obteve os valores médios, para os dois métodos, de $2679 \mathrm{~m} / \mathrm{s}$ e $2693 \mathrm{~m} / \mathrm{s}$, respectivamente, apresentando desvio máximo de $0,45 \%$. Esses resultados mostram que o sistema é adequado para realizar medidas de velocidade de propagação das ondas ultra-sônicas em diferentes meios e materiais, permitindo a caracterização dos mesmos em termos desse parâmetro.

Após realizar os procedimentos descritos por Langton et alli (1984), foi obtido o valor médio do índice BUA igual a $16,9 \mathrm{~dB} / \mathrm{MHz}$, com desvio padrão inferior a $\pm 3 \%$ entre as medições.

Os resultados experimentais apresentados convalidam o sistema proposto para auxílio no desenvolvimento de pesqui- 


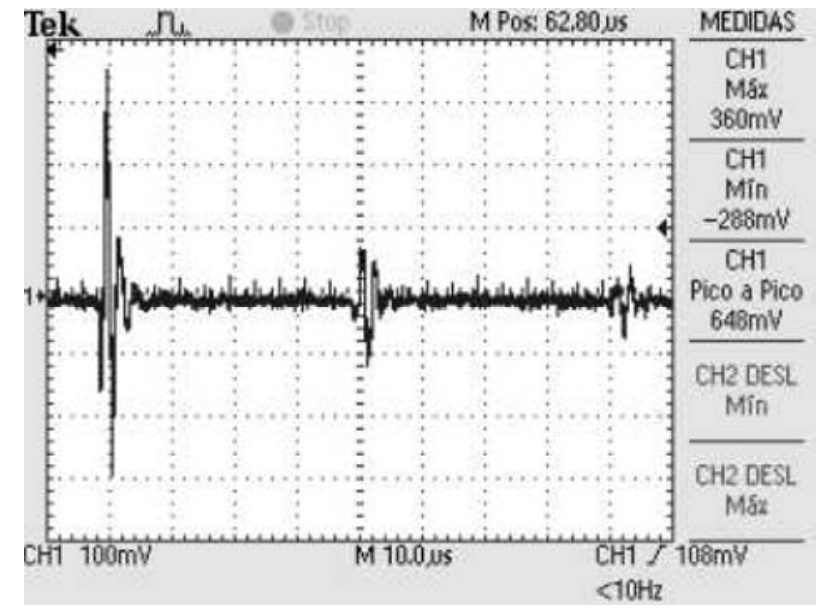

Figura 11: Sinal ultra-sônico captado pelo osciloscópio no transdutor receptor no modo transmissão-recepção.

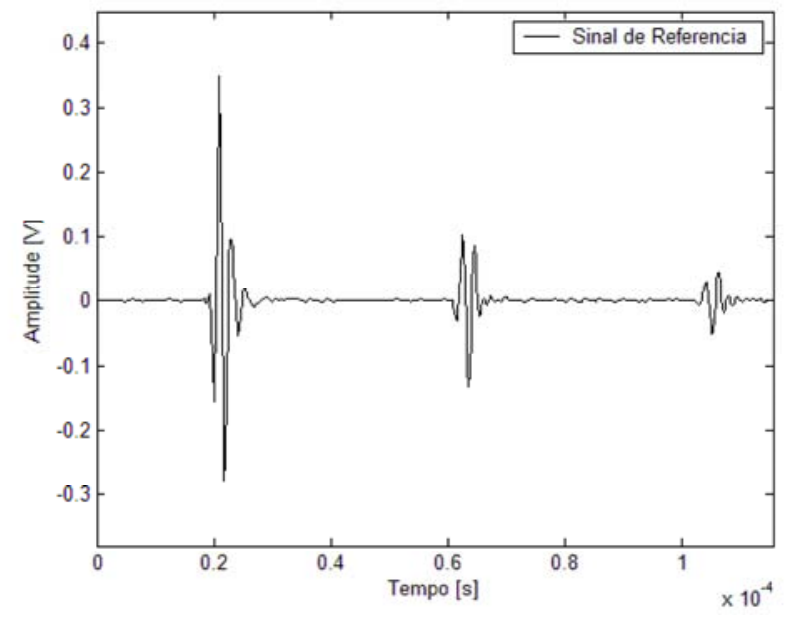

Figura 12: Sinal ultra-sônico obtido pelo sistema no modo transmissão-recepção.

sas na área de ultra-som tais como instrumentação eletrônica, construção e caracterização de transdutores piezoelétricos, mapeamento de campos acústicos, estudo da geração, propagação e detecção de ondas ultra-sônicas, ensaios nãodestrutivos de materiais e sua interação com tecidos e líquidos biológicos. Além disso, na área médica, após ser submetido a um Comitê de Ética em Pesquisa, credenciado pela Comissão Nacional de Ética em Pesquisa (CONEP/MS), o sistema poderá ser utilizado nas pesquisas do ultra-som no auxílio ao diagnóstico de doenças de forma não-invasiva, como por exemplo, no auxílio ao diagnóstico da osteoporose.

Trabalhos futuros poderão explorar e dar continuidade ao sistema proposto para a pesquisa dos parâmetros e aplicações do ultra-som, utilizando a alta capacidade de processamento

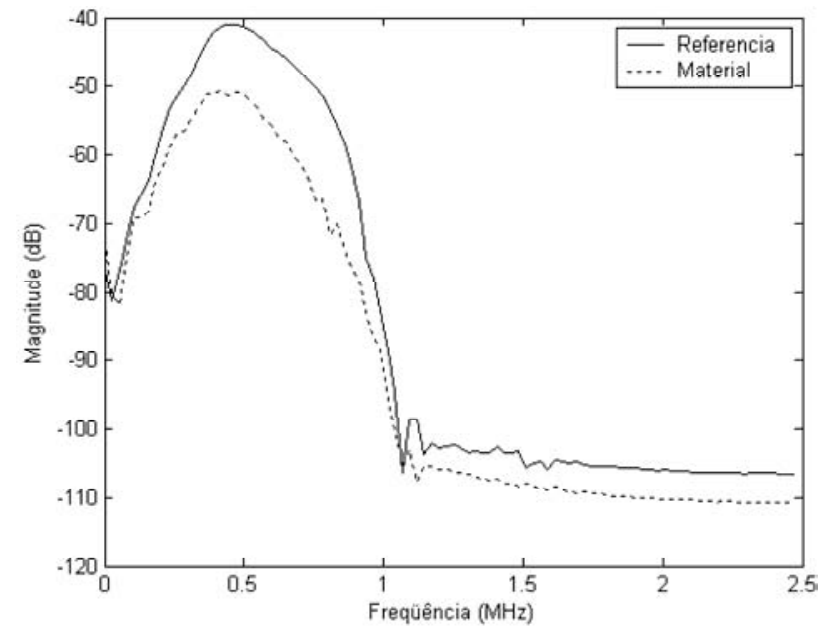

Figura 13: Transformadas de Fourier dos sinais de referência (contínuo) e transmitido através do acrílico (tracejado).

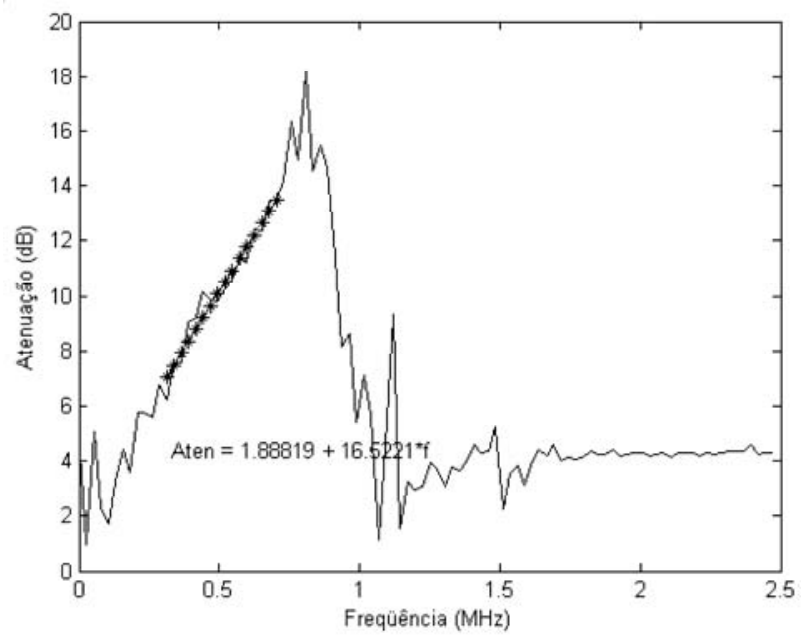

Figura 14: Curva de atenuação em função da freqüência $\alpha(f)$ para o acrílico.

dos DSPs para eliminar a necessidade do microcomputador.

\section{AGRADECIMENTOS}

Os autores agradecem ao Depto. de Engenharia Biomédica (DEB) da Faculdade de Engenharia Elétrica e de Computação (FEEC) da Universidade Estadual de Campinas (UNICAMP), pelo empréstimo dos transdutores de ultra-som utilizados durante o desenvolvimento do sistema, e à empresa Texas Instruments pelas amostras dos componentes cedidas. 


\section{REFERÊNCIAS}

Adamowski, J. C., Buiochi, F. Simon, C., Solva, E. C. N., Sigelmann, R. A. (1995). Ultrasonic measurement of density of liquids. Journal of the Acoustical Society of America, Vol. 97, No 1; pp. 354 - 361.

Bronzino, J. D. (1986). Biomedical engineering and instrumentation: Basic concepts and application. PWS Engineering, Boston.

Dorabiato, L. F. (2007). Sistema de ultra-som para caracterização de leite bovino. Dissertação de Mestrado, UTPFR, Curitiba-PR.

Dorabiato, L. F., Maia, J. M., Gamba, H. R. (2006). Caracterização de leite bovino por ultra-som. In: Anais do XX Congresso de Engenharia Biomédica, São Pedro; pp. 788-791.

Duarte, M. A., Machado, J. C. and Pereira, W. C. A. (1999). Método para classificação de ecos reais e de reverberação em meios homogêneos, multicamadas. Revista Brasileira de Engenharia Biomédica, Vol. 15, No 3; pp. 159-174.

Grimm, M. J. and Williams, J. L. (1993). Use of ultrasound attenuation and velocity to estimate Young's modulus in trabecular bone. IEEE Transactions on Ultrasound, Ferroelectrics, and Frequency Control, Vol. 42; pp. $62-63$.

Higuti, R. T., Bacaneli, F. Furukawa, C. M., Adamowski, J. C. (1999). Ultrasonic characterization of emulsions: milk and water in oil. IEEE Ultrasonics Symposium, Ceasars Tahoe; pp. $779-782$.

Hull, J. B, Langton, C. M., Barker, S. and Joner, A. R. (1996). Identification and characterization of materials by broadband ultrasonic attenuation analysis. Journal of $M a-$ terials Processing Technology, Vol. 56, No. 3; pp. 148157.

Kane, S. A. (2002). 9. Ultrasound Imaging, In: Introduction to Physics in Modern Medicine Disponível em http://www.haverford.edu/ physics-astro/course\{\_\}materials/ phys108b/211-10ultrasoundImaging.doc. Acesso em 15 set. 2008.

Kino, G. S. (1987). Acoustic Waves: Devices, Imaging, and Analog Signal Processing. Prentice Hall, New Jersey.

Langton, C. M., Palmer, S. B. and Porter, R. W (1984). The measurement of broadband ultrasonic attenuation in cancellous bone. Engineering in Medicine, Vol. 13, No. 2; pp. 89-91.
Maia, J. M. (2001). Sistema ultra-sônico para auxílio ao diagnóstico da osteoporose. Tese de Doutorado, UNICAMP/FEEC, Campinas-SP.

National Semiconductor, Inc (2005). LM723 Voltage Regulator. Disponível em: http://cache.national.com/ds/LM/LM723.pdf. Acesso em 15 set. 2008.

Nicholson, P. H. F., Lowet, G., Cheng, X. G., Boonen, S., Dequeker, J. and Van Der Perre. G. (1997). Ultrasonic measurement of the calcaneus: Investigation of some error sources and correlation with femoral strength. IEEE Engineering in Medicine and Biology Society, Vol. 2, No. 1; pp. 477-478.

Njeh, C. F., Saeed, I, Grigorian, M, Kender, D. L., Fan, B., Shepherd, J., McClung, M, Drake, W. M. and Genant, H. K. G. (2001). Assessment of bone status using speed of sound at multiple anatomical sites. Ultrasound in Medicine and Biology, Vol. 27, No. 10; pp. 1337-1345.

Oppenhein, A. V., Schafer, R. R. (1975). Digital signal processing. Prentice Hall, New Jersey.

Shung, K. K. (1996). From the Guest Editor - Advances in Ultrasound. IEEE - Engineering in Medicine and Biology, Vol. 15, No. 6; pp. 18-19.

Strelitzki, R, Evans, J. A. (1996). An investigation of the measurement of Broadband Attenuation in trabecular bone. Ultrasonics, Vol. 34, No. 2; pp. 785-791.

Texas Instruments, Inc. (2002). ADS5410 EVM - User's guide. Disponível em: http://focus.ti.com/ lit/ug/slau082/slau082.pdf. Acesso em 15 set. 2008.

Webb, S. (1988). The physics of medical imaging. S. Weeb, Adam Hilger, Bristol.

Wells, P. N. T. (1977). Ultrasonics in clinical diagnosis. Churchill Livingstone Inc., Edinburgh.

Wells, P. N. T. (1993). Advances in ultrasound techniques and instrumentation. Churchill Livingstone Inc, New York. 